\title{
Endovascular Approach of a Proximal Anterior Inferior Cerebellar Artery Aneurysm: Case Report
}

\section{Abordagem endovascular de um aneurisma proximal da artéria cerebelar anterior inferior: relato de caso}

\author{
Arquimedes Cavalcante Cardoso ${ }^{1}$ Luiz Eurípedes Almonde Santana Lemos ${ }^{2}$ \\ Marcos Alcino Soares Siqueira Marques Júnior ${ }^{3}$ \\ ${ }^{1}$ Universidade Federal do Piauí, Hospital Getúlio Vargas, Teresina, \\ Piauí, Brazil \\ 2 Universidade Estadual do Piauí, Piripiri, Piauí, Brazil \\ ${ }^{3}$ Centro Universitário Uninovafapi, Teresina, Piauí, Brazil \\ Address for correspondence Marcos Alcino Soares Siqueira Marques \\ Júnior, Centro Universitário Uninovafapi, Rua Vitorino Orthiges \\ Fernandes, 6123 - Uruguai, Teresina, Piauí, Brazil, 64073-505 \\ (e-mail: marcosalcinojr@gmail.com).
}

Arq Bras Neurocir 2017;36:58-61.

\begin{abstract}
Keywords

- anterior inferior cerebellar artery

- endovascular procedures

- intracranial aneurysm

\section{Resumo}

Palavras-chave

- artéria cerebelar anterior inferior

- procedimentos endovasculares

- aneurisma intracraniano

Anterior inferior cerebellar artery (AICA) aneurysms are extremely rare, accounting for only $0.75 \%$ of all intracranial aneurysms. The average age of patients suffering from those aneurysms found in the literature was 44 years, with no significant difference between the sexes. These aneurysms can manifest clinically through expansive symptoms in cerebellopontine angle or through signs and symptoms of subarachnoid hemorrhage, such as nausea, vomiting, headache, nystagmus and paresis. The gold standard exam for diagnosis is cerebral angiography. The treatment of these lesions is controversial. The main difficulty of the surgical treatment of these aneurysms is the location of the AICA, which lies close to critical neurovascular structures. In this article, we describe a proximal AICA aneurysm embolization without occlusion of the parent artery, with excellent results in the postoperative period.

Os aneurismas da artéria cerebelar anterior inferior (AICA) são extremamente raros, representando apenas $0,75 \%$ de todos os aneurismas intracranianos. A idade média de acometimento encontrada na literatura é de 44 anos, não havendo diferença significativa entre os sexos. A etiologia do aneurisma da AICA é controversa, porém, acreditase haver semelhanças com aneurismas em geral. Clinicamente, esses aneurismas podem manifestar sintomas expansivos no ângulo ponto-cerebelar, ou sinais e sintomas de hemorragia subaracnóidea (HSA), como náuseas, vômitos, cefaleia, nistagmo. O exame padrão-ouro para o diagnóstico é a angiografia cerebral. A maior controvérsia dos aneurismas da AICA é o tratamento. A principal dificuldade no tratamento cirúrgico desses aneurismas é a localização da AICA, perto de estruturas neurovasculares críticas. Neste artigo, descrevemos a embolização de um aneurisma proximal da AICA sem oclusão da artéria portadora, com excelentes resultados no pósoperatório.
\end{abstract}

received

September 22, 2016

accepted

October 19, 2016

published online

November 24, 2016
DOI http://dx.doi.org/ 10.1055/s-0036-1594258. ISSN 0103-5355.
Copyright (c) 2017 by Thieme Revinter

Publicações Ltda, Rio de Janeiro, Brazil

License terms

() (1) $\odot \circledast$ 


\section{Introduction}

Anterior inferior cerebellar artery (AICA) aneurysms are more common on the basilar artery apex, followed by aneurysms of the posterior inferior cerebellar artery (PICA), and superior cerebellar artery. ${ }^{1}$ Anterior inferior cerebellar artery aneurysms were first described in 1948 by Schwartz, ${ }^{2}$ and they are rare, representing only $\sim 0.1-0.5 \%$ of all posterior circulation aneurysms. ${ }^{1}$

These aneurysms represent a diagnostic and therapeutic challenge for the neurosurgeon. Since the first description by Schwartz, few cases of AICA aneurysms were reported. According to a 2002 review, until that year, only 62 cases of AICA aneurysms had been reported. ${ }^{1}$ These aneurysms present clinically with subarachnoid hemorrhage (SAH), and may be associated with cerebellar, spinal, or cranial nerves signs. $^{3}$

Since the first case described by Schwartz, the preferential treatment for these aneurysms has been the surgical approach. ${ }^{4}$ Although several surgical techniques have been described to access these aneurysms, surgery is generally made difficult due to the complexity of the adjacent neurovascular structures, such as the cranial nerves, the perforating arteries, and the brainstem.

The first embolization of an AICA aneurysm was successfully performed in $1999 .^{5}$ The endovascular technique was limited to embolization of the aneurysm with occlusion of the parent artery. In 2006, Kusaka et al described the first AICA aneurysm embolization preserving the parent artery. ${ }^{6}$ However, due to the rarity of these aneurysms, until 2011, only 26 cases of AICA aneurysm treated by embolization had been described in the literature. ${ }^{4}$

In this work, we present a case of a proximal AICA aneurysm treated by endovascular approach preserving the parent artery, with a good clinical outcome in the postoperative period.

\section{Case Report}

A female patient, aged 71, attended the emergency service complaining of severe headache, vomiting and confusion of progressive evolution in the four months prior to her visit.
A neurological examination revealed that the patient was drowsy (Hunt Hess grade III), but there were no motor or sensory deficits, and no cerebellar signs as well. The pupils had no abnormalities. A computed tomography (CT) scan was performed, and it showed a subarachnoid hemorrhage (SAH), grade Fisher III. The patient underwent a CT angiography (-Fig. 1), which demonstrated a proximal saccular AICA aneurysm, $\sim 0.4 \mathrm{~cm}$ after its origin in the basilar artery, measuring $\sim 0.3 \times 0.3 \times 0.3 \mathrm{~cm}$, with the neck measuring $0.2 \times 0.2 \mathrm{~cm}$.

The patient was transferred to this tertiary service, which specializes in the management of cerebrovascular disease, where the endovascular treatment was chosen after discussion among the hospital's neurosurgery team.

For embolization of the AICA aneurysm, a $6 \mathrm{~F}$ catheter guide was advanced through the left femoral artery until the vertebral artery. After that, a microcatheter was guided to the aneurysm, located in the proximal portion of the AICA. After microcatheterization, the aneurysm was filled with platinum coils (-Fig. 2). During the procedure, the parent artery was preserved. The patient had remained $\sim 24$ hours in the intensive care unit (ICU) environment. Due to her good clinical condition, the patient was discharged in the fourth postoperative day.

\section{Discussion}

The anterior inferior cerebellar artery emerges from the first to the second third of the basilar artery, having a single trunk bilaterally in $70 \%$ of patients, and a common trunk with the posterior inferior cerebellar artery (PICA) in $30 \%$ of cases. ${ }^{7}$ It branches to the pons, to the foramen of Luschka, to the middle cerebellar peduncle, and to the petrous surface of the cerebellum. Next to the complex formed by the VII and VIII cranial nerves, it bifurcates into the rostral and caudal trunks. Throughout its path, it is surrounded by critical neurovascular structures, such as the cranial nerves and the brainstem. ${ }^{3}$

Anterior inferior cerebellar artery aneurysms are extremely rare, accounting for only $0.75 \%$ of all intracranial

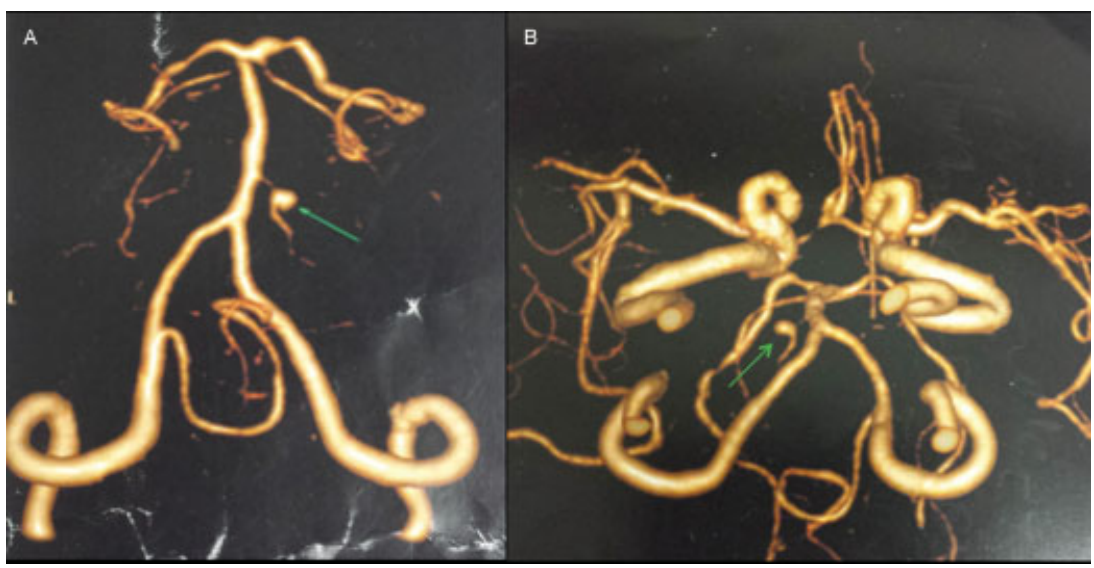

Fig. 1 Angio-tomography in posterior view (A) and in anterior view (B), showing a proximal saccular aneurysm (green arrows) in the right anterior inferior cerebellar artery, $\sim 0.4 \mathrm{~cm}$ after its origin in the basilar artery. 


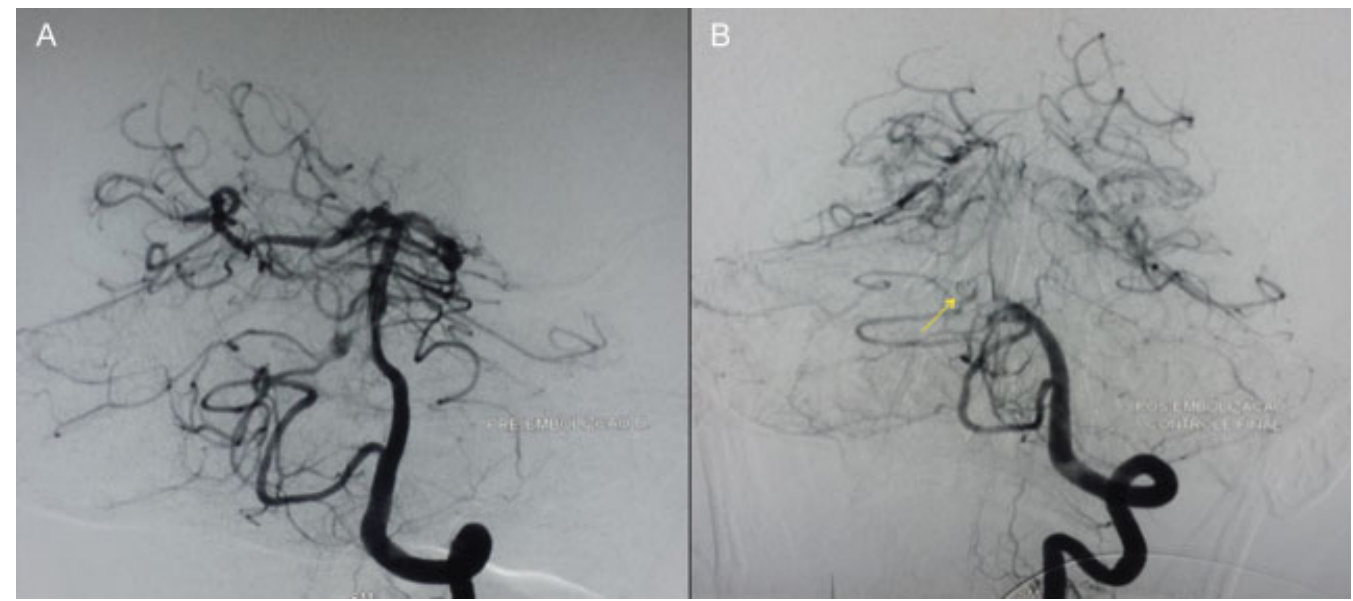

Fig. 2 A preoperative right oblique view arteriography $(A)$ and anterior postoperative (B) of the left vertebral artery, showing a proximal saccular AICA aneurysm filling with platinum coils (yellow arrow).

aneurysms. ${ }^{1}$ By 2002, only 62 cases of these aneurysms had been reported in the literature. ${ }^{1}$ In a large case series published in 2004, Gonzalez et al found only 34 (1.3\%) AICA aneurysms in a universe of more than 3,500 aneurysms described. ${ }^{8}$

The average age of the patients found in the literature was 44 years, with no significant difference between the sexes. There is no difference between laterality, with an almost equal involvement of the right and left sides. ${ }^{9}$ In our work, we describe a right AICA aneurysm in a 71-year-old female patient.

According Yamakawa et $\mathrm{al}^{10}$ AICA aneurysms can be classified into: proximal (extending from the origin of the AICA in the basilar artery to the meatal loop); medium (located in the meatal loop); and distal (following the end of the meatal loop until the distal AICA). According to Adorno et al, most AICA aneurysms described in the literature show a distal location, near the cerebellopontine angle, and are able to insinuate to the internal auditory canal. ${ }^{1}$ That would explain why most of these aneurysms have symptoms of involvement of the VII and VIII cranial nerves.

The etiology of AICA aneurysms is controversial; however, it is believed that they share similarities with aneurysms in general, such as hemodynamic stress, congenital fragility, and arterial injury by traumatic or inflammatory local process. The AICA aneurysm may accompany other malformations of the nervous system, such as arteriovenous malformations (AVMs) and Moyamoya disease. ${ }^{4}$

These aneurysms can be divided clinically into two groups: those that develop SAH affecting or not the cranial nerves (especially the VII and VII nerves); and those insidious aneurysms, which manifest as expansive symptoms in cerebellopontine angle. ${ }^{11}$ Other signs and symptoms, such as nausea, vomiting, headache, nystagmus and paresis are often found. ${ }^{1}$ In our case, we describe a patient with evolving symptoms of SAH and progressive severe headache.

The gold standard exam for diagnosis is cerebral angiography. ${ }^{1}$ However, other tests may be useful, such as CT angiography and magnetic resonance angiography.
The most controversial side to the AICA aneurysm is perhaps the treatment. Since the first report of an AICA aneurysm until 1999, all cases described in the literature were managed surgically. ${ }^{1}$

Depending on the anatomical characteristics of the AICA aneurysm, several surgical approaches can be used. Among the various approaches described in the literature, the most common are: sub occipital retrosigmoid access with or without petrosectomy; access through the middle temporal fossa (lateral approach); access by pterional or orbitozygomatic (anterolateral approaches); and, more rarely, the transfacial transclival approach. ${ }^{3}$

The main difficulty in the surgical treatment of these aneurysms is the location of the AICA, which lies close to critical neurovascular structures. According to Bambakidis et al, the main determinants for choosing surgery as a treatment option are: the craniocaudal location of the aneurysm in relation to the clivus; and the middle-lateral location along the artery path. According to these authors, the development of a corridor between the temporal bone and the posterior circulation is essential for a proper visualization of the AICA. ${ }^{3}$

In 1999, the first embolization of an AICA aneurysm was successfully performed, and the technique adopted involved the occlusion of the parent artery. ${ }^{5}$ The endovascular approach has revolutionized the treatment of posterior circulation aneurysms. This access eliminates many of the common surgical risks involved in the access to the AICA, making it a safe option. ${ }^{3}$

However, as the technique involved the total occlusion of the parent artery, the final result depended on the existence of collateral vessels and distal anastomoses of the AICA with other arteries. Unfortunately, in many cases this was not enough to prevent the appearance of complications. These result in different clinical manifestations, such as: dizziness; nausea; vomiting; dysarthria; facial weakness; Horner's syndrome; appendiceal dysmetria; hearing loss; and dysphagia. In severe cases of infarction of the AICA, coma, ophthalmoplegia, and quadriplegia may also occur. ${ }^{5,12,13}$ 
In 2006, Kusaka et al described a case of AICA aneurysm embolization that preserved the parent artery. ${ }^{6}$ The postoperative outcome was satisfactory.

Until 2011, only 26 cases of AICA aneurysm treated by endovascular approach had been described in the literature. Of these, 19 were distal aneurysms, and 7 were proximal aneurysms. There were 19 cases of occlusion of the parent artery, and in only 7 cases the parent artery was preserved. ${ }^{4}$

In this article, we describe a proximal AICA aneurysm embolization without occlusion of the parent artery, with excellent results in the postoperative period.

\section{Conclusion}

The rarity of AICA aneurysms justifies the limited experience in the treatment of these lesions. The endovascular approach has been gaining a lot of space currently, since it prevents the stress and complications of surgical trauma, especially in debilitated patients.

Even though our experience was satisfactory (performing an embolization of a proximal AICA aneurysm, preserving the parent artery), we cannot make generalizations, because few cases with similar conditions have been described in the literature. As a result, we conclude that these aneurysms remain a diagnostic and therapeutic challenge for the neurosurgeon.

\section{Conflict of Interest}

The authors have no conflict of interest to declare.

\section{References}

1 Adorno JOA, de Andrade GC. Aneurysm of the anterior inferior cerebellar artery: case report. Arq Neuropsiquiatr 2002;60(4): 1019-1024

2 Schwartz HG. Arterial aneurysm of the posterior fossa. J Neurosurg 1948;5(3):312-316
3 Bambakidis NC, Manjila S, Dashti S, Tarr R, Megerian CA. Management of anterior inferior cerebellar artery aneurysms: an illustrative case and review of literature. Neurosurg Focus 2009;26(5): E6

4 Suh SH, Kim DJ, Kim DI, et al. Management of anterior inferior cerebellar artery aneurysms: endovascular treatment and clinical outcome. AJNR Am J Neuroradiol 2011;32(1): 159-164

5 Suzuki K, Meguro K, Wada M, Fujita K, Nose T. Embolization of a ruptured aneurysm of the distal anterior inferior cerebellar artery: case report and review of the literature. Surg Neurol 1999;51(5):509-512

6 Kusaka N, Maruo T, Nishiguchi M, et al. [Embolization for aneurismal dilatation associated with ruptured dissecting anterior inferior cerebellar artery aneurysm with preservation of the parent artery: case report]. [in Japanese] No Shinkei Geka 2006;34(7):729-734

7 Baba T, Matsushima T, Fukui M, et al. [Relationship between angiographical manifestations and operative findings in 100 cases of hemifacial spasm]. [in Japanese] No Shinkei Geka 1988;16(12): 1355-1362

8 Gonzalez LF, Alexander MJ, McDougall CG, Spetzler RF. Anteroinferior cerebellar artery aneurysms: surgical approaches and outcomes-a review of 34 cases. Neurosurgery 2004;55(5): 1025-1035

9 Mizushima H, Kobayashi N, Yoshiharu S, et al. Aneurysm of the distal anterior inferior cerebellar artery at the medial branch: a case report and review of the literature. Surg Neurol 1999;52(2): 137-142

10 Yamakawa H, Hattori T, Tanigawara T, Sahashi Y, Ohkuma A. Intracanalicular aneurysm at the meatal loop of the distal anterior inferior cerebellar artery: a case report and review of the literature. Surg Neurol 2004;61(1):82-88, discussion 88

11 Dalley RW, Robertson WD, Nugent RA, Durity FA. Computed tomography of anterior inferior cerebellar artery aneurysm mimicking an acoustic neuroma. J Comput Assist Tomogr 1986;10(5): 881-884

12 Adams RD. Occlusion of the anterior inferior cerebellar artery. Arch Neurol Psychiatry 1943;49:765-770

13 Amarenco P, Lévy C, Cohen A, Touboul PJ, Roullet E, Bousser MG. Causes and mechanisms of territorial and nonterritorial cerebellar infarcts in 115 consecutive patients. Stroke 1994;25(1): $105-112$ 